\title{
Paediatric hospitalisations for lower respiratory tract infections in Mount Isa
}

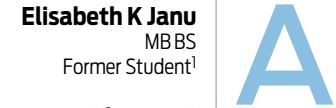
cute lower respiratory tract infections (ALRIs) are a major cause of paediatric morbid-

Bhavana Annabattula MBBS Former Student

Saampavi Kumariah MBBS Former Student

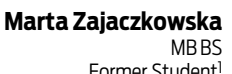

Former Student

\section{John S Whitehall} FRACP

Foundation Chair, an Professor of Paediatrics and Child Health

Matthew J Edwards MD, FRACP, FACMG Associate Professo Department of Paediatrics

Sanja Lujic BSc(Hons), MStats, MBiostats Biostatistician

lan B Masters MBBS FRACP PhD Director, ${ }^{3}$ and Member ${ }^{4}$

1 School of Medicine University of Western Sydney,

Sydney, NSW.

2 Centre for Health Research, University of Western

Sydney,

3Department of Respiratory Medicine, Royal Brisbane Children's Hospital, Brisbane, QLD.

4 Queensland Children's Medical Research Institute Brisbane, QLD.

Elisabeth.Janu@ health.nsw.gov.au

MJA 2014; 200: 591-594 doi: 10.5694/mjal3.10365 ity in regional Australia, particularly among Indigenous children, but there is a "dearth of data on aetiology and epidemiology $\ldots$ at the community level". ${ }^{1}$ Rates in the Northern Territory are reported to be among the highest in the world ${ }^{2}$ and similar rates have been suspected in neighbouring north-west Queensland. Mt Isa is a mining town in north-west Queensland with a base hospital that serves around 35000 people, of whom $19 \%$ are Indigenous. Its responsibility extends over an area of 380000 square kilometres to include several smaller hospitals and health centres generally regarded as remote area services. ${ }^{3}$ The epidemiology and features of paediatric ALRI in these remote communities have not been quantified previously. We aimed to redress this deficiency by reviewing admissions to Mt Isa Base Hospital of children with a diagnosis of bronchiolitis, pneumonia and bronchiectasis.

\section{Methods}

We conducted a retrospective review of all children $<15$ years of age admitted to Mt Isa Base Hospital from 1 January 2007 to 31 December 2011. International Classification of Diseases 10th revision, Australian modification classifications J10-J22 and J47 were used to identify all episodes of ALRI or bronchiectasis. Clinical, laboratory and radiological information in patients' medical charts was examined to confirm or reassign the diagnosis.

Bronchiolitis was defined as an acute lower respiratory tract infection in a child aged younger than 2 years with prior upper respiratory tract infection and signs of crepitations or wheeze. Pneumonia was defined as an acute febrile illness with respiratory symptoms and signs, associated with radiographically confirmed consolidation. Bronchiectasis was defined by chronic cough, repeated chest infections and abnormalities seen on high-resolution computerised tomography scans. ${ }^{4}$

\section{Abstrac}

Objective: To compare the rates of acute lower respiratory tract infection (ALRI) among children in north-west Queensland, according to age, sex and Indigenous status.

Design, setting and patients: Retrospective chart review of hospitalisations at Mt Isa Base Hospital, Queensland, from 1 January 2007 to 31 December 2011 among children $<15$ years of age.

Main outcome measures: Rates of admission for bronchiolitis, pneumonia and bronchiectasis, calculated using population data from the Australian Bureau of Statistics.

Results: There were 356 admissions for ALRI, involving 276 children. Of the 162 children aged $<12$ months old, 125 (77.2\%) were Indigenous. Hospitalisations increased over the study period, and rates were significantly higher among Indigenous children compared with non-indigenous children (24.1 v 4.5 per 1000 population per year). There were 195 admissions of 164 children with pneumonia, 126 (76.8\%) of whom were Indigenous. Annual rates for Indigenous children were higher than for non-Indigenous children (13.7 v 2.3 per 1000 population). Multiple admissions were common. One-third presented with gastrointestinal symptoms and signs. Pneumococcal disease persisted despite vaccination. There were 160 hospitalisations for bronchiolitis; 114 occasions (71.3\%) involved Indigenous children. Seven children had bronchiectasis; all were Indigenous.

Conclusion: Rates of ALRI in Mt Isa are comparable to those in the Northern Territory, which is reported to have rates of pneumonia among the highest in the world for children $<12$ months of age. Multiple admissions are common, suggesting an even higher rate of bronchiectasis. Pneumonia may present as gastrointestinal disease, and invasive pneumococcal infection must be suspected despite vaccination.

Indigenous status was declared by a parent or guardian on admission papers. Yearly and average annual hospitalisation rates were calculated using Australian Bureau of Statistics (ABS) data drawn from the 2006 and 2011 national censuses and categorised according to single age in years (0-14 years), Indigenous status and residence in the postcodes served by Mt Isa Base Hospital, including 4824, 4825, 4829, 4830 and 4890.5 Populations between census years (2007-2010) were extrapolated from the available ABS data. We calculated hospitalisation rates and $95 \%$ confidence intervals using Poisson distribution. Data were analysed using SPSS version 21.0 (IBM). The study was approved by the hospital ethics committee as a quality audit.

\section{Results}

Overall, there were 356 admissions for ALRI, involving 276 children. Of the 162 children aged less than 1 year, 125 (77.2\%) were Indigenous. Indigenous status could not be obtained for six admissions (1.7\%). Average annual hospitalisation rates by age group were five to eight times higher for Indigenous children than non-Indigenous children, with an overall rate of 24.1 per 1000 (95\% CI, 17.9-31.3) for Indigenous children and 4.5 per 1000 (95\% CI, 2.6-7.2) for non-Indigenous children (Box 1). Hospitalisation rates were highest for children under 12 months of age, and decreased with increasing age.

Multiple admissions were common. One child was admitted eight times; one was admitted seven times; three were admitted six times; five, four times; six, three times; and 31 children were admitted twice. There were no deaths.

The number of admissions for ALRI increased over the study period (Box 2), with rates increasing from 8.1 per 1000 in 2007 to 13.9 per 1000 in 2011.

\section{Pneumonia}

A total of 164 children (Indigenous children, 126 [76.8\%]) were admitted with pneumonia on 195 occasions. The average annual hospitalisation rate was significantly higher for Indigenous children (13.71 per 1000 [95\% CI, 9.1-19.3 per 1000]) than for 


\begin{tabular}{|c|c|c|c|c|c|c|}
\hline \multirow[b]{2}{*}{ Condition and age group } & \multicolumn{2}{|c|}{ Indigenous } & \multicolumn{2}{|c|}{ Non-Indigenous } & \multicolumn{2}{|c|}{ All patients } \\
\hline & No. ${ }^{\dagger}$ & Rate $^{\ddagger}(95 \% \mathrm{Cl})$ & No. ${ }^{\dagger}$ & Rate $^{\ddagger}(95 \% \mathrm{Cl})$ & No. ${ }^{\dagger}$ & $\operatorname{Rate}^{\ddagger}(95 \% \mathrm{Cl})$ \\
\hline \multicolumn{7}{|l|}{ Pneumonia } \\
\hline$<12$ months & 28 & $39.4(13.4-87.1)$ & 5 & $3.8(0.1-20.9)$ & 33 & $14.2(5.4-29.6)$ \\
\hline $12-23$ months & 30 & $33.7(12.4-73.4)$ & 10 & $6.5(0.8-23.6)$ & 40 & $14.6(6.3-28.7)$ \\
\hline 24-59 months & 49 & $21.6(9.8-39.1)$ & 17 & $4.2(0.8-10.9)$ & 66 & $9.1(4.8-15.3)$ \\
\hline 5 years and over & 45 & 6.3 (2.9-11.9) & 11 & $1.0(0.1-3.1)$ & 56 & $2.6(1.3-4.6)$ \\
\hline Total & 152 & $13.7(9.1-19.3)$ & 43 & $2.3(1.0-4.5)$ & 195 & $5.8(4.1-7.9)$ \\
\hline \multicolumn{7}{|l|}{ Bronchiolitis } \\
\hline$<12$ months & 93 & $131.0(77.8-204.6)$ & 34 & $25.6(9.4-51.7)$ & 128 & $55.1(35.7-80.6)$ \\
\hline $12-23$ months & 21 & $23.6(6.1-57.5)$ & 8 & $5.2(0.4-21.0)$ & 32 & $11.7(4.0-23.8)$ \\
\hline Total & 114 & $71.3(44.3-106.0)$ & 42 & $14.7(6.0-27.6)$ & 160 & $32.1(22.0-45.1)$ \\
\hline \multicolumn{7}{|l|}{ All ALRI } \\
\hline$<12$ months & 122 & $171.8(108.3-251.5)$ & 39 & $29.3(11.8-56.8)$ & 162 & $69.7(47.1-97.1)$ \\
\hline $12-23$ months & 53 & $59.6(28.9-107.0)$ & 18 & $11.8(2.8-31.1)$ & 75 & $27.3(15.3-45.1)$ \\
\hline 24-59 months & 47 & $20.7(9.1-37.6)$ & 17 & $4.2(0.8-10.9)$ & 64 & $8.8(4.5-14.8)$ \\
\hline 5 years and over & 45 & $6.3(2.9-11.9)$ & 9 & $0.8(0.0-2.8)$ & 55 & $2.6(1.3-4.6)$ \\
\hline Total & 267 & $24.1(17.9-31.3)$ & 83 & $4.5(2.6-7.2)$ & 356 & $10.5(8.2-13.2)$ \\
\hline
\end{tabular}

non-Indigenous children (2.33 per 1000 [95\% CI, $1.0-4.5$ per 1000$])$. This preponderance of Indigenous disease persisted in all age groups (Box 1) and was highest in the youngest age group.

Multiple admissions were common. One child was admitted six times; two were admitted four times; one, three times; and 17 children were admitted twice. All were Indigenous except for two non-Indigenous children who were admitted twice.

Hospitalisations for pneumonia rose annually from 3.8 per 1000 (95\% CI, 2.5-6.0 per 1000) in 2007 to 9.2 per 1000 (95\% CI, 7.1-11.8 per 1000) in 2011 (Box 3). There were no statistically significant differences between average age at admission (3.99 v 3.85 years) and duration of stay $(4.89 \mathrm{v} 3.86$ days) for Indigenous compared with non-Indigenous children, respectively. Sixty-three children (32\%) lived in communities distant from Mt Isa.

Vomiting, abdominal pain and diarrhoea, associated with fever and toxicity, were major signs in 66 presentations (33.8\%). Blood was cultured during 159 hospitalisations (81.5\%). Bacteria were isolated from 19 of these specimens $(11.9 \%)$, of which 17 were from Indigenous children. Six Streptococcus pneumoniae species and two Haemophilus influenzae species were identified. The remainder were Staphylococcus species.

2 Trends in admissions of children aged < 15 years to Mount Isa Base Hospital for acute lower respiratory tract infections, by Indigenous status, year and quarter (Q), 2007-2011

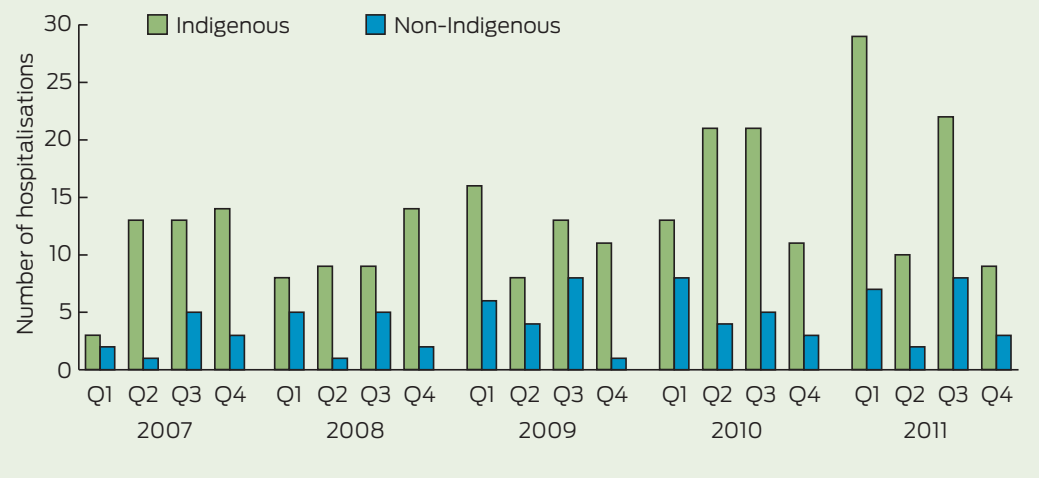

The ages of the children with pneumococcal disease were 5 months, 27 months (two children), 35 months, 7 years 4 months, and 9 years 2 months. Vaccination records showed that the 5-month-old infant had received two doses of 7-valent pneumococcal conjugate vaccine (7vPCV) and the other five children had received appropriate $7 \mathrm{vPCV}$, and 23-valent pneumococcal polysaccharide vaccine $(23 \mathrm{vPPV})$ at 18 months of age. Pneumococcal serotypes identified in the children included 1, 9N, 12F, 33F and 38.

Indigenous children had significantly lower haemoglobin $(\mathrm{Hb})$ levels but significantly higher white-cell counts (WCC) and elevated levels of C-reactive protein (CRP) than
non-Indigenous children (Box 4). Of the Indigenous children, $26.3 \%$ $(40 / 152)$ were anaemic $(\mathrm{Hb}<105 \mathrm{~g} / \mathrm{L})$ compared with only $7.0 \%$ (3/43) of non-Indigenous children. Raised WCC was not as sensitive an index of pneumonia as raised CRP. In 38 children, of whom 34 were Indigenous, CRP level exceeded $200 \mathrm{mg} / \mathrm{L}$ but in one-third of these the WCC was not elevated.

\section{Bronchiolitis}

There were 160 episodes of hospitalisation for bronchiolitis involving 119 children, of whom $66.4 \%$ (79) were Indigenous, accounting for $71.3 \%$ of admissions. One hundred and twentyeight admissions (80.0\%) involved children aged $<12$ months. The average 
3 Yearly trends in admissions of children aged $<15$ years to Mount Isa Base Hospital with acute lower respiratory tract infection (ALRI), 2007-2011

\begin{tabular}{|c|c|c|c|c|c|c|}
\hline \multirow[b]{2}{*}{ Year } & \multicolumn{2}{|c|}{ Pneumonia } & \multicolumn{2}{|c|}{ Bronchiolitis } & \multicolumn{2}{|c|}{ All ALRIs } \\
\hline & $\begin{array}{c}\text { No. of } \\
\text { admissions }\end{array}$ & $\begin{array}{l}\text { Annual rate per } 1000 \\
\text { population }(95 \% \mathrm{Cl})\end{array}$ & $\begin{array}{c}\text { No. of } \\
\text { admissions }\end{array}$ & $\begin{array}{l}\text { Annual rate per } 1000 \\
\text { population }(95 \% \mathrm{Cl})\end{array}$ & $\begin{array}{c}\text { No. of } \\
\text { admissions }\end{array}$ & $\begin{array}{l}\text { Annual rate per } 1000 \\
\text { population }(95 \% \mathrm{Cl})\end{array}$ \\
\hline 2007 & 26 & $3.8(2.5-5.6)$ & 29 & $28.8(19.3-41.3)$ & 55 & $8.1(6.1-10.5)$ \\
\hline 2008 & 26 & $3.8(2.5-5.6)$ & 28 & $27.7(18.4-40.0)$ & 54 & $7.9(6.0-10.4)$ \\
\hline 2009 & 35 & $5.2(3.6-7.2)$ & 34 & $33.5(23.2-46.9)$ & 69 & $10.2(7.9-12.9)$ \\
\hline 2010 & 46 & $6.8(5.0-9.1)$ & 39 & $38.4(27.3-52.4)$ & 85 & $12.8(10.2-15.8)$ \\
\hline 2011 & 62 & $9.2(7.1-11.8)$ & 31 & $30.4(20.7-43.1)$ & 93 & $13.9(11.2-17.0)$ \\
\hline
\end{tabular}

annual rate of hospitalisation among Indigenous children was 71.3 per 1000 , compared with 14.7 for non-Indigenous children. There was no significant difference between the ages of presentation for Indigenous and nonIndigenous children (8.0 months v 7.2 months), but length of stay was significantly longer for Indigenous children (3.95 days v 2.81 days; $P=0.008$ ). Boys were more commonly affected in both groups. Twenty-three children were admitted more than once; all were Indigenous. One child was admitted six times; two were admitted five times; one, four times; three, three times; and 16 children were admitted twice. There was no significant change in incidence in the study years.

\section{Bronchiectasis}

Seven children were shown to have bronchiectasis. All were Indigenous; four were boys; three children lived in Mt Isa but were known to spend considerable time in outlying communities; and four were from distant places including Doomadgee and Mornington Island. The median age at first presentation with a respiratory illness was 6 months (range, 1-13 months). The mean age at diagnosis of bronchiectasis was 5.9 months (SD, 3.7 months). Before diagnosis, the average number of presentations to hospital was 5.9 (SD, 6.57) and average number of admissions was 3.0 (SD, 1.91). The average annual hospitalisation rate was 4.1 per 1000 (95\% CI, 1.010.1 per 1000) among children aged less than 24 months.

No immediate genetic links were identified. Comorbidities were common. Five of the children had a past history of weight remaining around the third percentile throughout their lives; two had reached the 10th percentile. Four had been born prematurely and one was small for gestational age

\begin{tabular}{|c|c|c|c|}
\hline & $\begin{array}{l}\text { Indigenous children, } \\
\text { mean (SD) }\end{array}$ & $\begin{array}{c}\text { Non-Indigenous children, } \\
\text { mean (SD) }\end{array}$ & $P$ \\
\hline Haemoglobin (g/L) & 111.36 (22.48) & $124.00(13.26)$ & 0.001 \\
\hline C-reactive protein (mg/L) & $132.11(127.83)$ & 76.29 (75.54) & 0.005 \\
\hline White-cell count (×109/L) & $19.42(9.30)$ & $15.11(7.85)$ & 0.008 \\
\hline
\end{tabular}

at birth. In the past, one child had been hospitalised with osteomyelitis; two with bacterial meningitis; one with marasmus; and three with gastroenteritis.

\section{Discussion}

Our study provides evidence that ALRI is a major, increasing health burden in north-west Queensland, especially among Indigenous children, whose overall hospital admission rate for ALRIs was more than five times the rate for non-Indigenous children. Bronchiectasis was shown to be relatively common but only present in Indigenous children. In Mt Isa, this discrepancy (a 7.0 times greater average annual rate among Indigenous children) was twice as high as that reported elsewhere in Australia (a 3.2 times greater rate among Indigenous children 6 ).

The annual admission rates for Indigenous children with ALRI in $\mathrm{Mt}$ Isa are similar to those reported for the Northern Territory, where rates of pneumonia in children $<1$ year of age are declared to be among the highest in the world. ${ }^{2}$ Rates in the Northern Territory have been shown to be 57.5 per 1000 for children aged $<1$ year, 38.3 per 1000 for those aged 12 to 23 months, and 13.3 per 1000 for those aged 24 to 59 months, compared with respective rates for children in Mt Isa of $39.4,33.7$ and 21.6 per 1000 . The percentage of admissions for ALRI due to pneumonia was higher in $\mathrm{Mt}$
Isa (54\%) than in Alice Springs (20\%), and the rates for ALRI are increasing annually in north-west Queensland, whereas they appear to be stable in Alice Springs and to be decreasing in Western Australia.7

Our study showed that the presentation of pneumonia might not be straightforward. In one-third of presentations, gastrointestinal disease was considered the primary diagnosis because of abdominal pain, vomiting and diarrhoea. Pneumonia was revealed coincidentally on $x$-ray or in the search for the cause of associated tachypnoea and cough. Gastrointestinal symptoms are known to be common with pneumonia, but it is uncommon for them to constitute the admitting diagnosis, ${ }^{8}$ although this might reflect inexperience among junior staff.

Streptococcus pneumoniae was isolated from blood from only six Indigenous children, but it is known that rates of pneumonia due to that organism are much higher than indicated by blood culture results. ${ }^{9}$ Vaccination records showed that all of these children had received $7 \mathrm{vPCV}$; however, none of their infecting serotypes were included in that vaccine. Five had received appropriate $23 \mathrm{vPPV}$ as well as 7vPCV. Of these five, four were infected by serotypes included in $23 \mathrm{vPPV}(1,9 \mathrm{~N}$ and $33 \mathrm{~F})$, confirming reduced immunogenicity of this polysaccharide vaccine. ${ }^{10}$ Only one of these infecting serotypes (serotype 1) is included in the 13-valent PCV that has 
been dispensed in Australia since July 2011. This confirms the importance of considering invasive pneumococcal disease in any sick Indigenous child, regardless of vaccination status.

Raised CRP appears to be a more sensitive test than raised WCC. Indeed, in one-third of patients with pneumonia and a very high CRP, the WCC was not elevated.

The rates of hospitalisation for bronchiolitis in Mt Isa for Indigenous children (71.3 per 1000 population per year) and for non-Indigenous children (14.7 per 1000 per year) were lower than the overall rate in Alice Springs (190 per 1000), 11 but mildly affected children may have remained in distant communities around the Gulf of Carpentaria. In any case, Indigenous rates were similar to those reported for coastal Darwin ${ }^{12}$ and Townsville, 13 and for indigenous populations in the United States. ${ }^{14}$ The ages of first admission, repetitions of admission, lengths of stay and predominance of bronchiolitis were also similar to Darwin ${ }^{12}$ and Townsville. ${ }^{13}$ Unlike in Central and Western Australia, 15 the rate of bronchiolitis does not appear to be increasing in Mt Isa.

The prevalence of reported bronchiectasis among children in Mt Isa is lower than that reported for Alice Springs $^{13}$ (4.1 per 1000 per year v 14.7 per 1000 per year), but both far exceed the prevalence of cystic fibrosis in nonIndigenous children (0.035 per 1000). ${ }^{16}$ Findings regarding the characteristics of preceding respiratory disease were similar in Mt Isa and Alice Springs: early onset of multiple presentations and hospitalisations, and association with undernutrition and anaemia, premature birth and likelihood of living far from the city. ${ }^{7}$

Why Indigenous children are predisposed to ALRI and chronic bronchiectasis remains unknown. Possibilities include prematurity and intrauterine growth restriction, undernutrition, exposure to cigarette smoke, aspiration of infected nasopharyngeal secretions and social factors of overcrowded living conditions, poor hygiene and lack of access to medical care. Many of the children are members of common extended families, raising the question of the role of inherited polymorphisms in genes involved in immunity or inflammation. Such polymorphisms have been reported for certain racial groups. ${ }^{17}$ Indigenous Australians have a common gene polymorphism that leads to low serum levels of the anti-inflammatory cytokine interleukin-10 in those who smoke, ${ }^{18}$ invoking a mechanism for the adverse respiratory consequences associated with smoking.

Our retrospective study has the standard weakness of not being able to differentiate viral from bacterial disease on clinical and radiological grounds, especially on retrospective analysis. Also, we did not personally review each $\mathrm{x}$-ray in accordance with the World Health Organization recommendations for end point diagnosis of pneumonia. ${ }^{19}$ We accepted the radiologists' reports: if consolidation was reported we diagnosed pneumonia unless the clinical picture and the isolation of virus demanded categorisation as bronchiolitis. Given that viral bronchiolitis may cause consolidation, we may have overestimated the incidence of pneumonia at the expense of bronchiolitis. Conversely, had we relied on the WHO definition, we may have underestimated the incidence of bacterial pneumonia in favour of bronchiolitis. ${ }^{20}$ Overall, we would have underestimated the incidence of ALRI in Mt Isa because some children would have remained in outlying centres and others would have been transported directly to Townsville for intensive care.

In conclusion, given the rise of ALRI in north-west Queensland, the Indigenous health gap is widening despite national aspirations to close it. More attention needs to be paid to this distant region.

\section{Competing interests: No relevant disclosures.}

\section{Received 24 Mar 2013, accepted 10 Nov 2013.}

1 O'Grady K-AF, Chang AB. Lower respiratory infections in Australian Indigenous children. J Paediatr Child Health 2010; 46: 461-465.

2 O'Grady K-AF, Taylor-Thomson DM, Chang $A B$, et al. Rates of radiologically confirmed pneumonia as defined by the World Health Organization in Northern Territory Indigenous children. Med J Aust 2010; 192: 592-595.

3 Mount Isa Centre for Rural and Remote Health. Our region - Mount Isa Health Service District. James Cook University, 2007. http://www. micrrh.jcu.edu.au/Our-Region (accessed May 2014).

4 Kapur N, Masel JP, Watson D, et al. Bronchoarterial ratio on high-resolution
CT scan of the chest in children without pulmonary pathology. Chest 2011; 139: 1445-1450.

5 Australian Bureau of Statistics. 2011 Tablebuilder basic. Canberra: ABS, 2013. (ABS Cat. No. 2072.0.) http://www.abs.gov. au/websitedbs/censushome.nsf/home/ tablebuilder (accessed Oct 2013).

6 Australian Bureau of Statistics, the Australian Institute of Health and Welfare. The health and welfare of Australia's Aboriginal and Torres Strait Islander peoples, 2005. Canberra: ABS, 2005. (ABS Cat. No. 4704.0.) http://www. abs.gov.au/ausstats/abs@.nsf/mf/4704.0 (accessed Oct 2013).

7 Moore HC, Lehmann D, de Klerk N, et al. Reduction in disparity for pneumonia hospitalisations between Australian Indigenous and non-Indigenous children. J Epidemiol Community Health 2012; 66: 489-494.

8 Toikka P, Virkki R, Mertsola J, et al. Bacteremic pneumococcal pneumonia in children. Clin Infect Dis 1999; 29: 568-572.

9 Mufson MA. Pneumococcal infections. JAMA 1981; 246: 1942-1948.

10 Tan TQ. Pediatric invasive pneumococcal disease in the United States in the era of pneumococcal conjugate vaccines. Clin Microbiol Rev 2012; 25: 409-419.

11 Bolisetty S, Wheaton G, Chang AB. Respiratory syncytial virus infection and immunoprophylaxis for selected high-risk children in Central Australia. Aust J Rural Health 2005; 13: 265-270.

12 O'Grady K-AF, Torzillo PJ, Chang AB. Hospitalisation of Indigenous children in the Northern Territory for lower respiratory illness in the first year of life. Med J Aust 2010; 192: 586-590.

13 Reeve CA, Whitehall JS, Buettner PG, et al. Predicting respiratory syncytial virus hospitalisation in Australian children. J Paediatr Child Health 2006; 42: 248-252.

14 Peck AJ, Holman RC, Curns AT, et al. Lower respiratory tract infections among American Indian and Alaska Native children and the general population of U.S. children. Pediatr Infect Dis J 2005; 24: 342-351.

15 Moore H, Burgner D, Carville K, et al. Diverging trends for lower respiratory infections in nonAboriginal and Aboriginal children. J Paediatr Child Health 2007; 43: 451-457.

16 Valery PC, Torzillo PJ, Mulholland K, et al. Hospital-based case-control study of bronchiectasis in Indigenous children in Central Australia. Pediatr Infect Dis J 2004; 23 : 902-908.

17 Thiel S, Kolev M, Degn S, et al. Polymorphisms in mannan-binding lectin (MBL)-associated serine protease 2 affect stability, binding to MBL, and enzymatic activity. J Immunol 2009; 182: 2939-2947.

18 Moscovis SM, Gordon AE, Madani OM, et al. Interleukin-10 and sudden infant death syndrome. FEMS Immunol Med Microbiol 2004; 42: 130-138.

19 Cherian T, Mulholland EK, Carlin JB, et al. Standardized interpretation of paediatric chest radiographs for the diagnosis of pneumonia in epidemiological studies. Bull World Health Organ 2005; 83: 353-359.

20 Madhi SA, Klugman KP. World Health Organization definition of "radiologicallyconfirmed pneumonia" may under-estimate the true public health value of conjugate pneumococcal vaccines. Vaccine 2007; 25 : 2413-2419. 